\title{
An experimental study on the use of lycopene to prevent infertility due to acute oxidative ovarian damage caused by a single high dose of methotrexate
}

\author{
Can Turkler ${ }^{1, A-F}$, Taylan Onat ${ }^{2, C, E}$, Engin Yildirim ${ }^{3, D-F}$, Selcuk Kaplan ${ }^{4, D-F}$, \\ Gulce Naz Yazicici,A,B,F, Renad Mammadov ${ }^{6, A-C}$, Mukadder Sunar, ${ }^{7, B, E, F}$ \\ ${ }^{1}$ Department of Gynecology and Obstetrics, Faculty of Medicine, Erzincan Binali Yıldıım University, Turkey \\ ${ }^{2}$ Department of Gynecology and Obstetrics, Faculty of Medicine, Bozok University, Yozgat, Turkey \\ ${ }^{3}$ Department of Gynecology and Obstetrics, Faculty of Medicine, Hitit University, Corum, Turkey \\ ${ }^{4}$ Department of Gynecology and Obstetrics, Faculty of Medicine, Adiyaman University, Turkey \\ ${ }^{5}$ Department of Histology and Embryology, Faculty of Medicine, Erzincan Binali Ylldırım University, Turkey \\ ${ }^{6}$ Department of Pharmacology, Faculty of Medicine, Erzincan Binali Yıldırım University, Turkey \\ ${ }^{7}$ Department of Anatomy, Faculty of Medicine, Erzincan Binali Ylldırım University, Turkey \\ A - research concept and design; $\mathrm{B}$ - collection and/or assembly of data; $\mathrm{C}$ - data analysis and interpretation; \\ $D$ - writing the article; $E$ - critical revision of the article; $F$ - final approval of the article
}

Address for correspondence

Can Turkler

E-mail: dr_canturkler@yahoo.com

Funding sources

None declared

Conflict of interest

None declared

\section{Acknowledgements}

We thank Professor Halis Suleyman of the Erzincan Binali YIldırım University Department of Pharmacology (Faculty of Medicine) for his technical support and suggestions.

Received on February 19, 2019

Reviewed on June 17, 2019

Accepted on August 18, 2019

Published online on January 21, 2020

Cite as

Turkler C, Onat T, Yildirim E, et al. An experimental study on the use of lycopene to prevent infertility due to acute oxidative ovarian damage caused by a single high dose of methotrexate Adv Clin Exp Med. 2020;29(1):5-11. doi:10.17219/acem/111809

DOI

10.17219/acem/111809

Copyright

Copyright by Author(s)

This is an article distributed under the terms of the

Creative Commons Attribution 3.0 Unported (CC BY 3.0)

(https://creativecommons.org/licenses/by/3.0/)

\section{Abstract}

Background. Methotrexate (MTX) is an antineoplastic agent, which increases the level of reactive oxygen species (ROS) and decreases the level of antioxidants. Lycopene, is a potent antioxidant, which is used because of its protective effect against tissue damage.

Objectives. The aim of this study was to determine the effect of lycopene on ovarian MTX-induced injury in rats.

Material and methods. Rats $(n=36)$ were randomly divided into 3 equal groups: a group with MTX only $(M G, n=12)$, a group with lycopene and MTX (LMG, $n=12)$, and a healthy control group ( $H C G, n=12)$. Then, malondialdehyde (MDA), myeloperoxidase (MPO) and total glutathione (tGSH) levels and histopathological findings were examined in the ovaries of rats. Apart from the histopathological and biochemical evaluation, the reproductive performance of the experimental groups was also examined.

Results. Our study demonstrated that, in ovarian tissues of rats administered MTX, there was a decrease in the levels of tGSH, while MDA and MPO were increased, but it is observed that these ratios are reversed in the LMG $(p<0.05)$. It also has been proven that a single, high-dose use of MTX causes infertility in female rats, prolongs the gestation period and reduces the number of offspring.

Conclusions. Lycopene pretreatment ameliorates the MTX induced ovarian injury and infertility in rats through its antioxidative activities.

Key words: methotrexate, infertility, oxidative stress, rat, lycopene 


\section{Introduction}

Methotrexate (MTX) is a chemotherapeutic agent that is a folic acid antagonist. This agent, which acts by inhibiting the activity of dihydrofolate reductase, is frequently used in the treatment of autoimmune and malignant diseases. ${ }^{1}$ It has been found that this agent, which is also frequently used in ectopic and molar pregnancy treatments, increases the level of free oxygen radicals and pro-inflammatory molecules. ${ }^{2}$ It is also gonadotoxic and decreases the number of ovarian follicles. In this way, it is thought to cause infertility, especially in young patients. ${ }^{3}$ When published literature is examined, some researchers have stated that there is no negative effect on the ovarian reserve at the doses used for the treatment of ectopic pregnancy. ${ }^{4}$ However, there is a controversy about the effect of MTX therapies on the ovarian reserve and infertility. Various methods have been used to evaluate ovarian reserve. Methods used to determine the ovarian reserve include a primordial follicle count, the amount of gonadotropins and the level of anti-Müllerian hormone. ${ }^{5}$ However, the occurrence of pregnancy is the best clinical parameter illustrating the ovarian reserve and the fertility of a female.

Lycopene is a kind of carotenoid, which is a potent antioxidant. It has lipophilic properties and is found in large amounts in red fruits, for example in tomatoes. Lycopene supplementation is very important to stop the harmful effects of free oxygen radicals. Lycopene is one of the most studied antioxidant agents because of its protective effect against tissue damage. In addition, it shows anticancer activity. ${ }^{6}$ It also has the effect of regulating detoxification systems, clearing reactive oxygen species (ROS) and increasing the transmission between gap-junctions. ${ }^{7,8}$ An examination of the published literature reveals that lycopene has hepatoprotective and neuroprotective features. ${ }^{9,10}$ A further effect of lycopene is that it decreases the complications associated with diabetes mellitus (DM). ${ }^{11,12}$ However, there is no study indicating its protective effect against acute ovarian damage induced by a single, high dose of MTX.

In light of this information, the aim of this study was to determine the effect of lycopene on ovarian MTXinduced injury in rats. Apart from the histopathological and biochemical evaluation, the reproductive performance of the experimental groups was also examined.

\section{Material and methods}

\section{Animals}

The recommendations of the Animal Research: Reporting of In Vivo Experiments (ARRIVE) guidelines for animal care were taken into consideration. A total of $36 \mathrm{Wis}-$ tar albino female rats weighing 260-272 g were randomly chosen for use in the study. The animals were housed and fed at room temperature $\left(22-24^{\circ} \mathrm{C}\right)$ prior to the experiment. This study was carried out in accordance with international guidelines on the ethical use of animals (Ethics Committee Date and No.: 22.11.2018-12/210).

\section{Experimental groups}

Rats were randomly divided into 3 groups before the following experimental conditions were applied: a group with $20 \mathrm{mg} / \mathrm{kg}$ of MTX only (MG; $\mathrm{n}=12$ ), a group with $5 \mathrm{mg} / \mathrm{kg}$ of lycopene and $20 \mathrm{mg} / \mathrm{kg}$ of MTX (LMG; $\mathrm{n}=12$ ), and a healthy control group (HCG; $\mathrm{n}=12$ ).

\section{Chemical substances}

The MTX used in the study was provided by MedIlac (Istanbul, Turkey), thiopental sodium was provided by Ibrahim Etem Ulagay (Istanbul, Turkey) and lycopene was provided by Solgar (Leonia, USA).

\section{Experimental procedure}

Lycopene was given orally via gavage at a dose of $5 \mathrm{mg} / \mathrm{kg}$ to the LMG $(n=12)$ of rats. ${ }^{13}$ In the other 2 groups, the same volume of normal sunflower oil $(0.5 \mathrm{~mL})$ was used as the solvent. One hour after the administration of the lycopene and the solvent, the LMG and MG were injected intraperitoneally (i.p.) with a single dose of MTX $(20 \mathrm{mg} / \mathrm{kg}){ }^{2}$ The lycopene and the solvent were administered once a day for 5 days. At the end of this application, 6 rats from each group (MG, LMG and HCG) were euthanized with a high dose of anesthesia $(50 \mathrm{mg} / \mathrm{kg}$ of thiopental sodium i.p.) and the ovaries were removed. Malondialdehyde (MDA), myeloperoxidase (MPO) and total glutathione (tGSH) levels were measured in the ovarian tissues. The ovarian tissues were also examined histopathologically. All test results were evaluated by comparing the groups together.

Three mature male rats were added to each group of 6 female rats for reproduction. The groups with female and male rats together were kept in appropriate laboratory settings for 2 months. During this period, the pregnant rats were kept in a suitable environment in separate cages. In 2 months, the rats that did not get pregnant and did not give birth were considered infertile.

\section{Biochemical analysis of ovarian tissues}

\section{Measurement of MDA}

The levels of tissue lipid peroxidation were determined by predicting MDA levels (Cayman Chemical; Cat. No: 10009055; Michigan, USA) using the thiobarbituric acid test involving spectrophotometrical measurements at a wavelength of $532 \mathrm{~nm}$ used by Ohkawa et al. ${ }^{14}$ The results were expressed as $\mu \mathrm{mol} / \mathrm{g}$ of protein. 


\section{Measurement of MPO}

A modified method by Wei and Frenkel was adopted for the determination of MPO activity (Cayman Chemical; Item No. 600620) in the homogenate. ${ }^{15}$ The increases in the absorbance values were measured at a wavelength of $510 \mathrm{~nm}$. Absorbance was measured spectrophotometrically at a wavelength of $412 \mathrm{~nm}$. The results were expressed as U/g of protein.

\section{Measurement of tGSH}

The level of tGSH (Cayman Chemical; Cat. No. 703002) in the tissues was measured according to the process described by Sedlak and Lindsay. ${ }^{16}$ The absorbance value was determined at a wavelength of $412 \mathrm{~nm}$ spectrophotometrically. The results were expressed as $\mathrm{nmol} / \mathrm{g}$ of protein.

\section{Histopathological analysis of ovarian tissues}

After routine tissue follow-up, 5-micron sections were obtained for histopathological evaluation. These sections were stained with hematoxylin and eosin $(\mathrm{H} \& \mathrm{E})$. The ovarian tissues were evaluated under an optical microscope (Olympus BX 51; Olympus Corp., Shinjuku, Tokyo, Japan) and the images were captured using a digital camera (Olympus DP 71). Histopathological examination was carried out using a blind histological evaluation method.

\section{Statistical analysis}

A statistical evaluation of the results was carried out using one-way analysis of variance (ANOVA) and SPSS v. 22.0 software (IBM Corp., Armonk, USA). The Tukey multiple comparison test was used to determine the differences between groups. The level of significance was set at $\mathrm{p}<0.05$.

\section{Results}

The biochemical results of this study are summarized in Fig. 1. The MDA level in the ovarian tissue was measured to be $1.2 \pm 0.2 \mu \mathrm{mol} / \mathrm{g}$ of protein in the HCG and $4.3 \pm 0.4 \mu \mathrm{mol} / \mathrm{g}$ of protein in the MG. When compared to the HCG, the increase in MDA level in MG was significant ( $<<0.05)$. A $5 \mathrm{mg} / \mathrm{kg}$ dose of lycopene reduced the level of MDA $(1.7 \pm 0.2 \mu \mathrm{mol} / \mathrm{g}$ of protein $)$ significantly compared to the MG ( $\mathrm{p}<0.05)$.

When the other 2 groups were compared with the MG, MPO was significantly increased in the MG $(7.1 \pm 0.7 \mathrm{U} / \mathrm{g}$ of protein), but the value in the LMG $(2.8 \pm 0.6 \mathrm{U} / \mathrm{g}$ of protein) was close to the HCG $(1.9 \pm 0.7 \mathrm{U} / \mathrm{g}$ of protein) $(\mathrm{p}<0.05)$. Methotrexate application significantly decreased the tGSH level in the ovarian tissue of rats compared to the HCG $(\mathrm{p}<0.05)$. The tGSH levels were measured to be $6.8 \pm 0.2 \mathrm{nmol} / \mathrm{g}$ of protein in the HCG

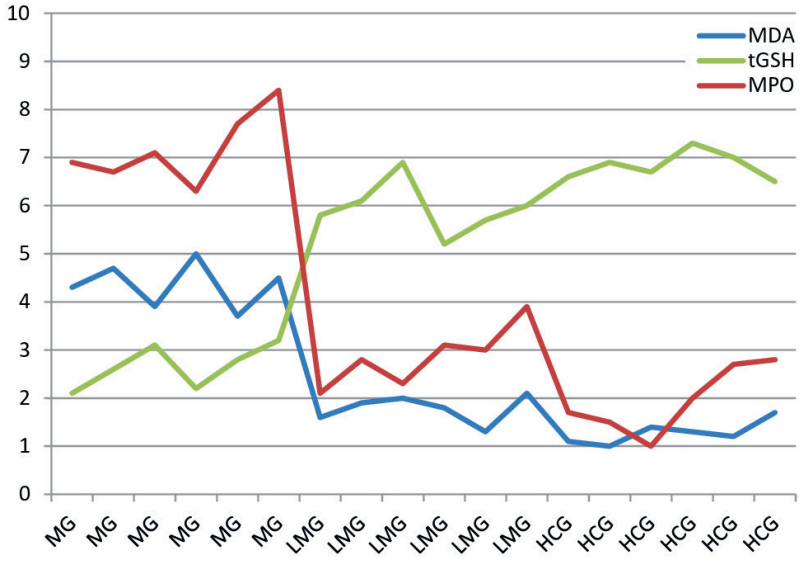

Fig. 1. Malondialdehyde (MDA), myeloperoxidase (MPO) and total glutathione (tGSH) levels of ovarian tissues for 3 groups.

HCG - healthy control group; MG - methotrexate group; LMG - lycopene + methotrexate group.

and $2.6 \pm 0.4 \mathrm{nmol} / \mathrm{g}$ of protein in the MG. It was found that $5 \mathrm{mg} / \mathrm{kg}$ of lycopene, by comparison with the MG, significantly improved the tGSH level $(5.9 \pm 0.5 \mathrm{nmol} / \mathrm{g}$ of protein) in the LMG ( $\mathrm{p}<0.05)$.

A histological examination of ovaries in the HCG revealed that the ovarian tissue structure had a normal cortex and medulla (Fig. 2). In the MG, a microscopic examination showed that there were apparent edema in the follicular cells and the interstitial area, vascular dilation and congestion, polymorphonuclear cell infiltration, and degeneration in developing follicles (Fig. 3,4). In the ovaries of rats treated with lycopene prior to MTX, we observed a marked decrease in edema in the follicular cells and interstitial area, mild

Table 1. The reproduction results of healthy control group

\begin{tabular}{|c|c|c|c|c|c|}
\hline \multirow{2}{*}{ Rats } & Gestation & Infertile & Number & \multicolumn{2}{|c|}{ Gender of offspring } \\
\cline { 5 - 7 } & period [days] & rat & of offspring & male & female \\
\hline 1. & 26 & - & 8 & 2 & 6 \\
\hline 2. & 29 & - & 6 & 3 & 3 \\
\hline 3. & 25 & - & 10 & 3 & 7 \\
\hline 4. & 31 & - & 8 & 4 & 4 \\
\hline 5. & 33 & - & 8 & 2 & 6 \\
\hline 6. & 30 & - & 9 & 3 & 6 \\
\hline
\end{tabular}

Table 2. The reproduction results of Lycopene + MTX group

\begin{tabular}{|c|c|c|c|c|c|}
\hline & \multirow{2}{*}{ Rats } & Gestation & Infertile & Number & \multicolumn{2}{|c|}{ Gender of offspring } \\
\cline { 5 - 6 } & period [days] & rat & of offspring & male & female \\
\hline 1. & 31 & - & 6 & 4 & 2 \\
\hline 2. & 28 & - & 8 & 5 & 3 \\
\hline 3. & 33 & - & 7 & 5 & 2 \\
\hline 4. & - & + & - & - & - \\
\hline 5. & 35 & - & 8 & 5 & 3 \\
\hline 6. & 30 & - & 6 & 3 & 3 \\
\hline
\end{tabular}




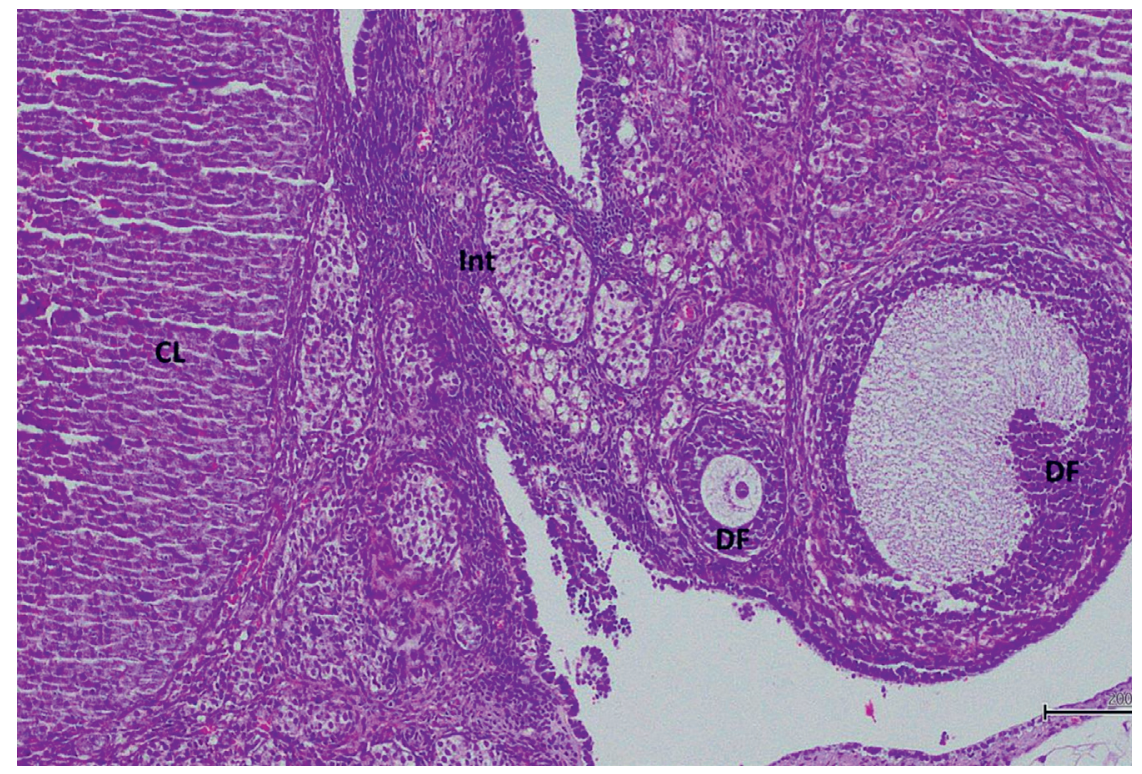

Fig. 2. Hematoxylin and eosin staining in ovarian tissue in the control group

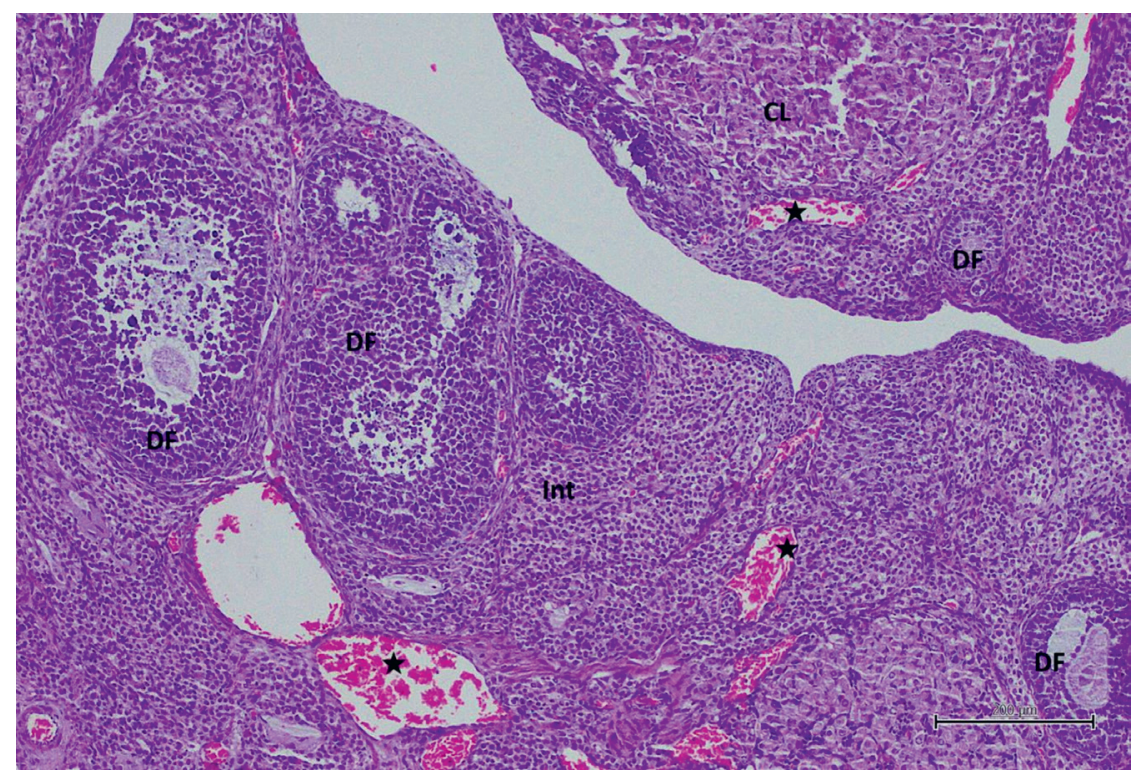

Fig. 3. Hematoxylin and eosin staining in ovarian tissue in the MTX group

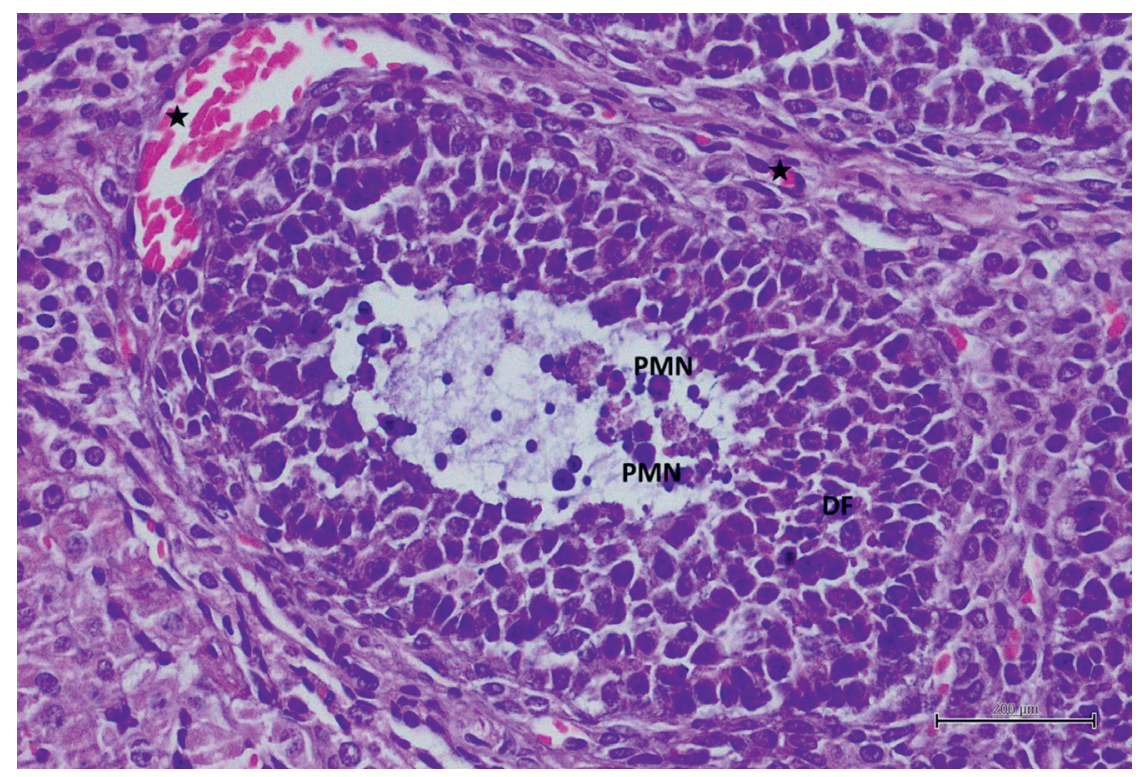

Fig. 4. Hematoxylin and eosin staining in ovarian tissue in the MTX group 


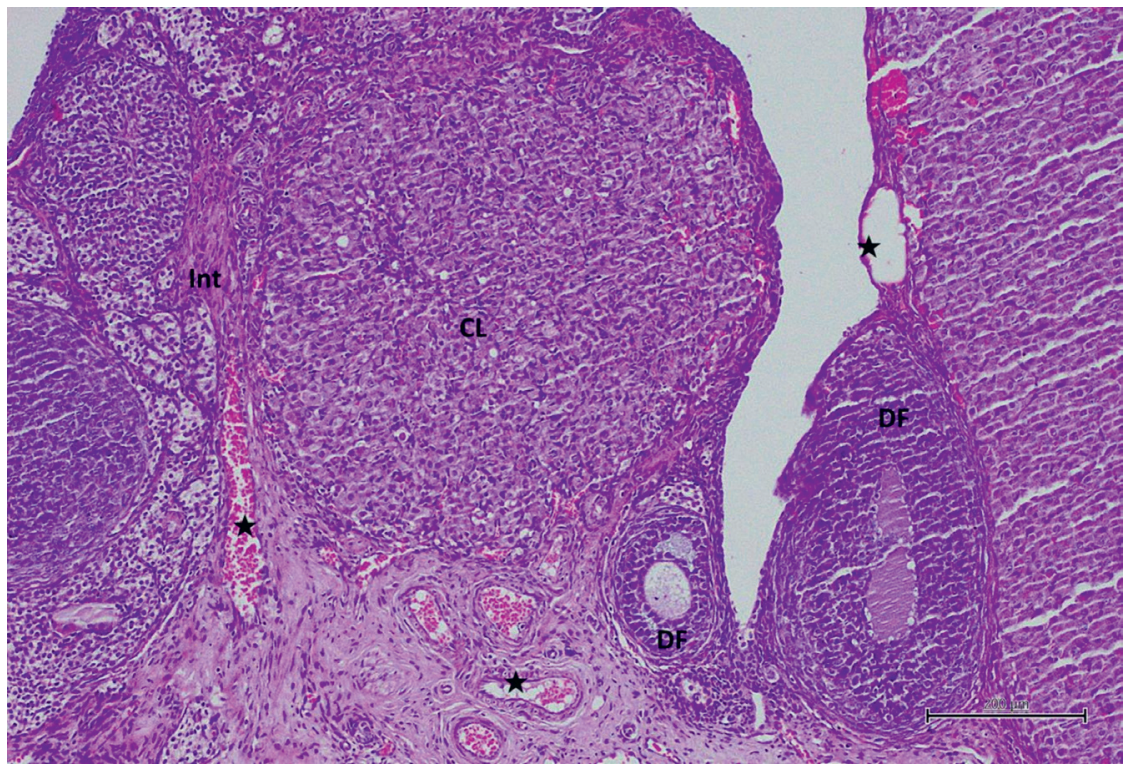

Fig. 5. Hematoxylin and eosin staining in ovarian tissue in the MTX + lycopene group

Table 3. The reproduction results of MTX group

\begin{tabular}{|c|c|c|c|c|c|}
\hline \multirow{2}{*}{ Rats } & Gestation & Infertile & Number & \multicolumn{2}{|c|}{ Gender of offspring } \\
\cline { 5 - 6 } & period [days] & rat & of offspring & male & female \\
\hline 1. & - & + & - & - & - \\
\hline 2. & - & + & - & - & - \\
\hline 3. & 47 & - & 4 & 3 & 1 \\
\hline 4. & - & + & - & - & - \\
\hline 5. & - & + & - & - & - \\
\hline 6. & - & + & - & - & - \\
\hline
\end{tabular}

vascular dilatation and congestion, and a normal follicular structure (Fig. 5).

The reproduction results of the experimental groups are summarized in Table 1, 2 and 3. Table 1 shows that there were no infertile rats in the HCG, and the mean gestational period was 29 days. A total of 49 offspring, 17 male and 32 female, were produced by this group. Table 2 shows that there was 1 infertile rat in the LMG, and the mean gestational period was 31.4 days. A total of 35 offspring, 22 male and 13 female, were produced by this group. Table 3 shows that there were 5 infertile rats in the MG, and the mean gestational period was 47 days. A total of 4 offspring, 3 male and 1 female, were produced by this group. When the average number of offspring was examined, there were 8.1 in the HCG, 7 in the LMG and 4 in the MG. The fewness of the average number of offspring in the MG than the other 2 groups was statistically significant $(p<0.05)$.

\section{Discussion}

In recent years, the number of people diagnosed with cancer at an early age has increased due to the development of cancer awareness in the community, developments that allow early detection of cancer and perhaps environmental factors. ${ }^{17}$ One of the most frequently asked questions among young patients diagnosed with cancer is whether they will have children after surgery, chemotherapy or radiotherapy. In particular, MTX is one of the most commonly used chemotherapeutics, both on its own and in combination therapy.

Published literature describes the use of MTX in various doses and at various times. Although the low-dose MTX used for ectopic pregnancy treatment does not affect the ovarian reserve, it is known that the use of high-dose MTX in chemotherapy does adversely affect it. ${ }^{3,4,18}$ For this reason, ovarian tissue in this study was examined histopathologically in single and high-dose MTX-treated experimental groups, and the levels of oxidant/antioxidant molecules in the ovarian tissue were determined. It further investigated whether lycopene has a protective effect using this experimental model.

When the published literature is examined, there are many studies which prove that lycopene protects testicular tissue and improves the quality of sperm cells. ${ }^{19,20}$ Therefore, lycopene and other antioxidant molecules have been used to treat male infertility. ${ }^{21}$ However, there are no studies on the effects of lycopene on the reproductive capacity of women or female animals.

In this study, it was found that MDA and MPO levels increased in the ovarian tissues after MTX was applied and that the level of tGSH decreased. In the LMG, the antioxidant molecules (tGSH) increased and oxidant molecules (MDA and MPO) decreased. This investigation illustrated 2 results:

- using a single, high dose of MTX produces oxidative stress in ovarian tissues, and

- lycopene can combat this MTX-induced damage.

The histopathological examination of the ovarian tissues of the rats also supported these biochemical results.

Each group was subjected to reproductive testing on equal terms after biochemical and histopathological sampling. Reproduction occurred across the entire HCG over 
the two-month reproductive period. However, in the MG, it was found that only 1 rat had given birth and that the duration of the pregnancy was quite long. In addition, only 1 rat was not pregnant in the LMG, and the duration of the pregnancy was similar to the HCG. The average number of offspring in the LMG and HCG was similar. Thus, it has been proven that a single, high dose use of MTX causes infertility in female rats, prolongs the gestation period and reduces the number of offspring. However, when we looked at the gender ratios of the offspring in the experimental groups, an unexpected result was seen. The female gender was dominant in the offspring obtained from the HCG, but this ratio was reversed in the LMG and MG. In a study by Lantinga et al., 124 female patients aged from 18 to 45 years who received chemotherapy and radiotherapy for childhood cancers were evaluated in terms of reproductive and menstrual cycles. ${ }^{22}$ When they looked at the offspring of patients who had received chemotherapeutic treatment other than 6-mercaptopurine (6MP) and 6-thioguanine (6TG), the male gender was dominant, like in this study. This result is thought to be due to a defect of the X-chromosome caused by chemotherapeutic drugs. Testosterone, and its active form dihydrotestosterone, have a major role in the development of the male genital organs. ${ }^{23}$ Also, we know that the production of adrenal gland hormones increase when the mother is stressed. ${ }^{24}$ In our study, the second reason for the high number of male offspring in the experimental groups receiving MTX may be the oxidative stress caused by MTX in the mother and the resulting increase in the androgenic hormone level. Aksoy et al. found that the number of male offspring increased due to the oxidative stress on the remaining ovaries in unilateral ovariectomized rats. ${ }^{25}$ This finding agrees with the published literature.

In a study on poultry, lycopene was found to inhibit both natural ovarian aging and d-galactose-induced ovarian aging. ${ }^{26}$ In 1992, Stahl et al. reported that the measurements of beta-carotene and lycopene levels from the diet in human plasma and 7 different human tissues (liver, adrenal gland, testis, kidney, ovary, and fat and brain stem tissue). ${ }^{27}$ In this study, it was reported that the lycopene level was found to be the lowest in the ovarian tissue. Considering the positive and curative effects of lycopene on ovarian tissue, lycopene supplementation is beneficial for clinical conditions caused by oxidative stress.

The experiment features some limitations. Firstly, there is no data about the ameliorative effect of lycopene on single, high-dose MTX-induced ovarian injuries in published literature. Secondly, the experiment used a single dose of lycopene $(5 \mathrm{mg} / \mathrm{kg}$ ). Future research should use different doses of lycopene to determine the mean effective dose for antioxidant activity. Thirdly, MTX-induced ovarian injury was demonstrated by the morphological modifications in the ovarian tissue. Any damage in the other organs and systems should be evaluated in future studies. Fourthly, in order to fully understand the reason for the high number of male offspring in the experimental groups receiving the MTX treatment, the offspring resulting from abortion should be examined.

\section{Conclusions}

When chemotherapeutic drugs such as MTX are used in high doses, they cause tissue damage through oxidative stress. If a woman undergoes this treatment at a young age, it is apparent that she has an infertility problem. This study showed that with lycopene, MTX-induced ovarian damage and infertility could be prevented. As a result, lycopene-like molecules with antioxidant properties may prevent infertility as an additional effect to chemotherapy.

\section{ORCID iDs}

Can Turkler (D) https://orcid.org/0000-0003-2716-0322 Taylan Onat (D) https://orcid.org/0000-0002-8920-1444 Engin Yildirim (D) https://orcid.org/0000-0001-7937-4141 Selcuk Kaplan (D) https://orcid.org/0000-0002-2887-6165 Gulce Naz Yazici (D) https://orcid.org/0000-0002-6989-997X Renad Mammadov (D) https://orcid.org/0000-0002-5785-1960 Mukadder Sunar (D) https://orcid.org/0000-0002-6744-3848

\section{References}

1. Mercantepe T, Kalkan Y, Tumkaya L, Sehitoglu I, Mercantepe F, Yıldırmıs S. Protective effects of tumor necrosis factor alpha inhibitors on methotrexate-induced pancreatic toxicity. Adv Clin Exp Med. 2018;27(6):715-720.

2. Yucel Y, Oguz E, Kocarslan S, et al. The effects of lycopene on methotrexate-induced liver injury in rats. Bratis/ Lek Listy. 2017;118(4):212-216.

3. Sonmezer M, Oktay K. Fertility preservation in female patients. Hum Reprod Update. 2004;10(3):251-266.

4. Uyar I, Yucel OU, Gezer C, et al. Effect of single-dose methotrexate on ovarian reserve in women with ectopic pregnancy. Fertil Steril. 2013;100(5):1310-1313.

5. Benian A, Guralp O, Uzun DD, Okyar A, Sahmay S. The effect of repeated administration of methotrexate (MTX) on rat ovary: Measurement of serum antimullerian hormone (AMH) levels. Gynecol Endocrinol. 2013;29(3):226-229.

6. Bhuvaneswari V, Nagini S. Lycopene: A review of its potential as an anticancer agent. CurrMed Chem Anticancer Agents. 2005;5(6):627-635.

7. Astorg $P$, Gradelet $S$, Bergès $R$, Suschetet $M$. Dietary lycopene decreases the initiation of liver preneoplastic foci by diethylnitrosamine in the rat. Nutr Cancer. 1997;29(1):60-68.

8. Zhang LX, Cooney RV, Bertram JS. Carotenoids enhance gap junctional communication and inhibit lipid peroxidation in C3H/10T1/2 cells: Relationship to their cancer chemopreventive action. Carcinogenesis. 1991;12(11):2109-2114.

9. Malekiyan R, Abdanipour A, Sohrabi D, Jafari Anarkooli I. Antioxidant and neuroprotective effects of lycopene and insulin in the hippocampus of streptozotocin-induced diabetic rats. Biomed Rep. 2019; 10(1):47-54.

10. Abdel-Rahman HG, Abdelrazek HMA, Zeidan DW, Mohamed RM, Abdelazim AM. Lycopene: Hepatoprotective and antioxidant effects toward bisphenol A-induced toxicity in female Wistar rats. Oxid Med Cell Longev. 2018;2018:5167524.

11. Uçar S, Pandir D. Furan induced ovarian damage in non-diabetic and diabetic rats and cellular protective role of lycopene. Arch Gynecol Obstet. 2017;296(5):1027-1037.

12. Yildiz M, Sandikci M. Changes in rat ovary with experimentally induced diabetes and the effects of lycopene on those changes. Rom JMorphol Embryol. 2016;57(2 Suppl):703-713.

13. Limpens J, Schröder FH, de Ridder CM, et al. Combined lycopene and vitamin E treatment suppresses the growth of PC-346C human prostate cancer cells in nude mice. J Nutr. 2006;136(5):1287-1293.

14. Ohkawa $\mathrm{H}$, Ohishi $\mathrm{N}$, Yagi K. Assay for lipid peroxides in animal tissues by thiobarbituric acid reaction. Anal Biochem. 1979;95(2):351-358.

15. Bradley PP, Priebat DA, Christensen RD, Rothstein G. Measurement of cutaneous inflammation: Estimation of neutrophil content with an enzyme marker. J Invest Dermatol. 1982;78(3):206-209. 
16. Sedlak J, Lindsay RH. Estimation of total, protein-bound, and nonprotein sulfhydryl groups in tissue with Ellman's reagent. Anal Biochem. 1968;25(1):192-205.

17. Siegel RL, Miller KD, Jemal A. Cancer Statistics, 2017. CA Cancer J Clin. 2017;67(1):7-30.

18. Boots CE, Gustofson RL, Feinberg EC. Does methotrexate administration for ectopic pregnancy after in vitro fertilization impact ovarian reserve or ovarian responsiveness? Fertil Steril. 2013;100(6):1590-1593.

19. Türk G, Ceribaşi AO, Sakin F, Sönmez M, Ateşşahin A. Antiperoxidative and anti-apoptotic effects of lycopene and ellagic acid on cyclophosphamide-induced testicular lipid peroxidation and apoptosis. Reprod Fertil Dev. 2010;22(4):587-596.

20. Bucak MN, Ataman MB, Başpınar N, et al. Lycopene and resveratrol improve post-thaw bull sperm parameters: Sperm motility, mitochondrial activity and DNA integrity. Andrologia. 2015;47(5):545-552.

21. Majzoub A, Agarwal A. Systematic review of antioxidant types and doses in male infertility: Benefits on semen parameters, advanced sperm function, assisted reproduction and live-birth rate. Arab J Urol. 2018;16(1):113-124.
22. Lantinga GM, Simons AH, Kamps WA, Postma A. Imminent ovarian failure in childhood cancer survivors. Eur J Cancer. 2006;42(10): 1415-1420.

23. Bao AM, Swaab DF. Sexual differentiation of the human brain: Relation to gender identity, sexual orientation and neuropsychiatric disorders. Front Neuroendocrinol. 2011;32(2):214-226.

24. Hines M, Brook C, Conway GS. Androgen and psychosexual development: Core gender identity, sexual orientation and recalled childhood gender role behavior in women and men with congenital adrenal hyperplasia (CAH). J Sex Res. 2004;41(1):75-81.

25. Aksoy AN, Aydın F, Topdagı Yılmaz EP, Batmaz G, Suleyman B. The effect of controlled reperfusion in the prevention of infertility caused by ischemia induced in the contralateral ovary in rats with unilateral ovariectomy. Gynecol Obstet Invest. 2015;80(3):199-205.

26. Liu X, Lin X, Zhang S, et al. Lycopene ameliorates oxidative stress in the aging chicken ovary via activation of Nrf2/HO-1 pathway. Aging (Albany NY). 2018;10(8):2016-2036.

27. Stahl W, Schwarz W, Sundquist AR, Sies H. Cis-trans isomers of lycopene and beta-carotene in human serum and tissues. Arch Biochem Biophys. 1992;294(1):173-177. 